\title{
Drug prescription appropriateness in the elderly: an Italian study
}

This article was published in the following Dove Press journal:

Clinical Interventions in Aging

10 February 2017

Number of times this article has been viewed

\author{
Nicola Allegri' \\ Federica Rossi \\ Federica Del Signore ${ }^{2}$ \\ Paolo Bertazzoni ${ }^{3}$ \\ Roberto Bellazzi ${ }^{4}$ \\ Giorgio Sandrini ${ }^{5}$ \\ Tomaso Vecchi' \\ Davide Liccione' \\ Alessia Pascale ${ }^{6}$ \\ Stefano Govoni ${ }^{6}$ \\ 'Department of Brain and Behavioral \\ Sciences, University of Pavia, ${ }^{2}$ Pavia \\ and Vigevano Neuropsychological \\ Center for Alzheimer's Disease, \\ 3"Bertazzoni" Pharmacy General \\ Partnership, Vigevano, ${ }^{4}$ Nephrology \\ and Dialysis Ward, Civil Hospital \\ of Vigevano, ${ }^{5} \mathrm{C}$. Mondino National \\ Institute of Neurology Foundation, \\ IRCCS, ${ }^{6}$ Department of Drug \\ Sciences, Section of pharmacology, \\ University of Pavia, Pavia, Italy
}

Purpose: Correct drug prescription in the elderly is a difficult task that requires careful survey of the current pharmacological therapies. In this article, we reviewed the drug prescriptions provided to 860 persons aged 65 years or over, residing in a small city of Lombardy, Italy.

Methods: Subjects were recruited from a local nursing home, the Pavia and Vigevano Neuropsychological Center for Alzheimer's Disease, general practitioners' offices, and the local University of the Third Age. For each patient, the amount of potentially inappropriate prescriptions (PIPs), sedative and anticholinergic load (SL and AL, respectively), and drug-drug interactions were evaluated.

Results: Widespread polypharmacy, giving rise to $10.06 \%$ of PIPs in the whole collection of prescriptions, was observed. In particular, PIPs mainly concern drugs acting at the central nervous system level, mostly benzodiazepines and antipsychotics. Moreover, approximately one-fourth of the subjects had an elevated SL and approximately one-tenth a high AL. Drug-drug interactions were frequent (266 requiring medical attention), up to five for each single patient. Of concern was the underuse of antidementia drugs: only 20 patients received a cholinesterase inhibitor or memantine, although 183 patients were potentially suitable for this treatment.

Conclusion: These results demonstrate the need to develop novel strategies aimed at improving the quality of drug prescription.

Keywords: drug prescription, elderly, Beers criteria, drug-drug interactions, sedative load

\section{Introduction}

Drug prescription inappropriateness represents an issue of major interest in clinical practice, since it increases the prevalence of drug-induced harms, with consequences related to patients' health ${ }^{1}$ and cost of care. ${ }^{2}$ This is particularly true for elderly people, whose frailty makes the choice of the correct drug prescription even more difficult. ${ }^{3}$

Appropriateness can be assessed by measuring explicit (criterion-based) or implicit (judgment-based) outcomes. ${ }^{4,5}$ In this regard, international explicit criteria have been developed to assess the pertinence of medications in the elderly, such as the Beers criteria, which was recently updated by the American Geriatrics Society, ${ }^{6-8}$ or the STOPP (Screening tool of older person's prescriptions)/START (Screening tool to alert doctors to right treatment). ${ }^{9}$ These measures mainly take into account the relationship between a particular drug and the specific medical case. However, it should be stressed that the evaluation of prescription appropriateness in the elderly represents a complex issue ${ }^{10}$ that should also include other clinical dimensions, such as the amount of prescribed drugs, ${ }^{11}$ drug-drug interactions, ${ }^{12}$ and the potential sedative and anticholinergic effects of the prescribed drugs. ${ }^{13,14}$

In this context, the aim of the present work was to evaluate the appropriateness of drug prescription using the Beers criteria and including the assessment of the aforementioned
Correspondence: Nicola Allegri Pavia and Vigevano Neuropsychological Center for Alzheimer's Disease,

Via Sacchetti I, 27029, Vigevano,

Pavia, Italy

Tel +39 38I 23709473

$\mathrm{Fax}+3938182225$

Email nicola.allegri@unipv.it
Clinical Interventions in Aging 2017:12 325-333

325

Dovepress f 5 in

http://dx.doi.org/10.21 147/CIA.SI 09125

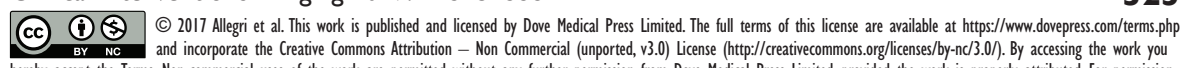
hereby accept the Terms. Non-commercial uses of the work are permitted without any further permission from Dove Medical Press Limited, provided the work is properly attributed. For permission for commercial use of this work, please see paragraphs 4.2 and 5 of our Terms (https://www.dovepress.com/terms.php). 
aspects in a group of 860 persons, aged $\geq 65$ years, residing in a small city of Lombardy, Italy.

\section{Methods}

As a part of a larger epidemiological study, neuropsychologists administered an anonymous questionnaire regarding prescribed medicines to 860 subjects. The study participants were divided into three groups: 1) belonging to a local nursing home (NH patients $-\mathrm{n}=142$ ); 2) coming to the local memory clinic (MC; Pavia and Vigevano Neuropsychological Center - Alzheimer Section) for a neurological examination (MC patients $-\mathrm{n}=572$ ); 3) volunteer subjects (VS patients $\mathrm{n}=146$ ), mainly recruited at the local University of the Third Age, at general practitioners' offices or in other community centers. The questionnaire included the age of the patient (in years), sex, Mini-Mental State Examination (MMSE) score, current illnesses and treatments. MMSE was assessed according to the Folstein and McHugh method, ${ }^{15}$ as adapted for the Italian population ${ }^{16}$ (range 0-30; normal range $>24$ ). The results on drug use were correlated with the demographic and clinical data. The demographic characteristics, which referred to both the whole sample and the subgroups, are reported in Table 1. Figures 1 and 2 give a more detailed picture of the heterogeneity, in terms of age and MMSE, of the participants coming for a neurological examination to the local MC.

\section{Appropriateness of the prescription}

Appropriateness of the prescription was analyzed by the use of the Beers criteria. ${ }^{8}$ In case of molecules available on the Italian market, but not included in the American Geriatrics Society list of medications, the drug was evaluated (ie, in terms of class, pharmacokinetics) and classified by the team of pharmacologists.
When applying the Beers criteria, specific care was taken regarding the diagnosis of the patient.

\section{Sedative load definition}

The sedative load (SL) was calculated for each subject according to a published model. ${ }^{13}$ Medications were classified as follows: Group 1, primary sedatives; Group 2, medications with sedation as a prominent side effect or preparations with a sedating component; Group 3, medications with sedation as a potential adverse effect; Group 4, all the other medications with no known sedative properties.

\section{Anticholinergic load definition}

The AL was calculated according to the scoring system of the Anticholinergic Drug Scale. ${ }^{17}$ On the Anticholinergic Drug Scale, drugs are rated from 0 to 3 , with level zero indicating no anticholinergic activity, and level 3 indicating an elevated anticholinergic activity. The anticholinergic scores relative to each drug taken by the patient were summed up to obtain the total score.

\section{Drug interactions}

Drug interactions were evaluated using the Drug Interactions Checker program available at the website (www. drugs.com/drug interactions.html) and further checked by a pharmacologist employing the Stockley's Drug Interactions ${ }^{18}$ international source.

\section{Statistics}

Drugs were classified according to the Anatomical Therapeutic Chemical (ATC) code, data were collected in an ad hoc created database and analyzed using the SPSS software version 15.0 (SPSS Inc., Chicago, IL, USA). ${ }^{19}$ Mean and standard deviation were calculated for each variable. For some

Table I Demographic characteristics of the patients

\begin{tabular}{|c|c|c|c|c|c|c|}
\hline Groups & Sex & Age & $\begin{array}{l}\text { Education } \\
\text { (years) }\end{array}$ & MMSE & $\begin{array}{l}\text { Number of } \\
\text { illnesses (range) }\end{array}$ & $\begin{array}{l}\text { Number of } \\
\text { prescriptions }\end{array}$ \\
\hline $\begin{array}{l}\text { Whole sample } \\
n=860\end{array}$ & $\begin{array}{l}\text { Males: } 295 \\
\text { Females: } 565\end{array}$ & $80.36 \pm 7.36$ & $4.79 \pm \mathrm{I} .4$ & $23.82 \pm 5.48$ & $3.91 \pm 2.17$ & $5.91 \pm 3.46$ \\
\hline $\begin{array}{l}\text { NH patients } \\
n=142\end{array}$ & $\begin{array}{l}\text { Males: } 43 \\
\text { Females: } 99\end{array}$ & $83.5 \pm 7.5^{\mathrm{a}}$ & $5.01 \pm 1.20^{\mathrm{b}}$ & $22.3 I \pm 5.92^{c}$ & $3.65 \pm 1.93$ & $7.89 \pm 3.92^{\mathrm{e}}$ \\
\hline $\begin{array}{l}\text { MC patients } \\
n=572\end{array}$ & $\begin{array}{l}\text { Males: } 185 \\
\text { Females: } 387\end{array}$ & $80.65 \pm 7.52^{\mathrm{a}}$ & $4.94 \pm 1.32^{b}$ & $22.9 I \pm 5.9 I^{c}$ & $4.16 \pm 2.22^{d}$ & $5.81 \pm 3.16^{\mathrm{e}}$ \\
\hline $\begin{array}{l}\text { VS } \\
n=146\end{array}$ & $\begin{array}{l}\text { Males: } 67 \\
\text { Females: } 79\end{array}$ & $76.16 \pm 7.19^{a}$ & $4.00 \pm 1.59^{b}$ & $28.33 \pm 2.3 I^{c}$ & $3.20 \pm 2.03^{d}$ & $4.36 \pm 3.24^{\mathrm{e}}$ \\
\hline
\end{tabular}

Notes: The table reports the main clinical-demographical data of the subjects recruited in this study, including the number of males and females, age, years of education, MMSE score, number of illnesses and prescriptions, all expressed as mean $\pm \mathrm{SD}$. ${ }^{\mathrm{a}} \mathrm{P}<0.00 \mathrm{I}$ : among all the three groups, ${ }^{\mathrm{b}} \mathrm{P}<0.00 \mathrm{I}$ : between $\mathrm{NH}$ patients and $\mathrm{VS}$ subjects and between MC patients and VS subjects, ${ }^{c} P<0.00$ I: between $\mathrm{NH}$ patients and VS subjects and between $M C$ patients and VS subjects, ${ }^{d} P<0.00 \mathrm{I}$ : between $M C$ patients and VS subjects, ${ }^{e} P<0.00 \mathrm{I}$ : among all the three groups.

Abbreviations: MC, memory clinic; MMSE, Mini-Mental State Examination; NH, nursing home; VS, volunteer subjects; SD, standard deviation. 


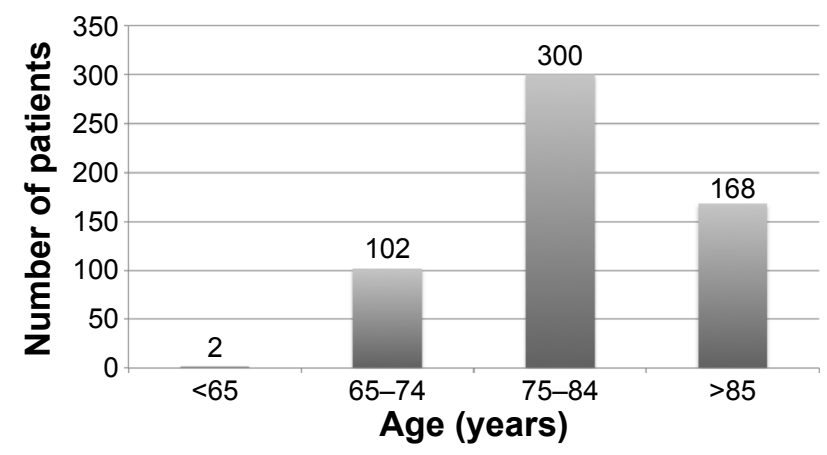

Figure I Age of $M C$ patients.

Note: Distribution of age in $M C$ patients.

Abbreviation: MC, memory clinic.

variables of interest, an analysis of variance (ANOVA) was performed. A $P$-value $<0.05$ was considered statistically significant. Moreover, to explore the relationship between some of the considered characteristics, a bivariate analysis based on Pearson's $r$ correlation was carried out.

\section{Results}

A total of 5,087 prescriptions was recorded for the 860 subjects examined in the study, corresponding to 472 molecules, with cardiovascular and central nervous system (CNS) drugs representing most of the sample ( $31.1 \%$ and $21.2 \%$, respectively). Considering the single subgroups, cardiovascular drugs were most frequently prescribed to $\mathrm{MC}$ and VS subjects (32.8\% and $38.8 \%$, respectively), while $\mathrm{NH}$ patients were mainly prescribed CNS and gastrointestinal drugs (27.3\% and $26.4 \%$, respectively).

The average number of prescriptions per patient in the whole sample was 5.91 (Table 1). To this regard, a significant difference was found among the three groups $(\mathrm{F}[2,857]=41,593 ; P<0.001)$, and post hoc analyses specifically revealed that, as expected, $\mathrm{NH}$ patients take a

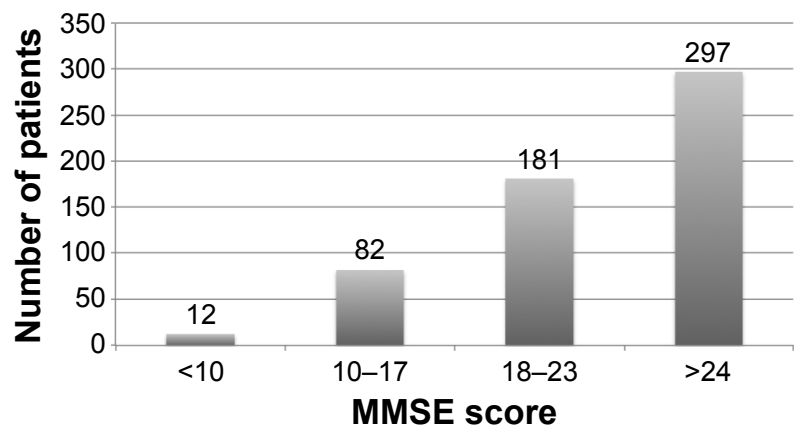

Figure 2 MMSE score of MC patients.

Note: Distribution of the MMSE score of the patients coming for a neurological examination to the local in MC.

Abbreviations: MC, memory clinic; MMSE, Mini-Mental State Examination. greater amount of drugs (7.89) compared with MC (5.81) and VS (4.36) subjects.

Within the range of age investigated (65-100 years), age did not correlate with the amount of prescriptions, neither in the whole sample $(r=-0.006 ; P=0.864)$, nor in $\mathrm{NH}$ and VS subjects ( $r=-0.143, P=0.089$ and $r=0.045, P=0.588$, respectively), although a negative correlation was observed in MC patients $(r=-0.123, P<0.05)$.

Not surprisingly, in the whole sample, the subjects who have a higher number of diseases also received more prescriptions $(r=0.480 ; P<0.001)$, and this was true even when considering each subgroup (NH: $r=0.477$, MC: $r=0.489$, VS: $r=0.593 ; P<0.001$ for all).

\section{Top ten prescriptions}

Table 2 reports ten drugs that were most frequently prescribed while Table 3 shows the complete distribution of the medications in the whole sample according to their relative ATC class. In the whole sample, almost one-third of the patients were taking acetylsalicylic acid (35.3\%), mainly for secondary prevention of cardiovascular and cerebrovascular events. Furosemide and ramipril held the second (22.4\%) and third (14.2\%) place, respectively. Proton pump inhibitors were also frequently used; indeed, combining esomeprazole and omeprazole, 220 prescriptions were reached, corresponding to $25.5 \%$ of patients. No psychotropic drugs were present within the top ten prescriptions. Similar data were obtained when analyzing each subgroup of patients. However, it is noteworthy to mention that psychotropic drugs were prescribed in the top ten prescriptions in $\mathrm{NH}$ patients, where quetiapine held the fifth place, and in VS subjects, where lorazepam held the ninth place. This finding is confirmed by the data referring to the complete distribution of medications according to their relative ATC class, where psychotropic drugs (the main prescribed drugs acting on the nervous system) held the second place (Table 3).

\section{Potentially inappropriate drug prescriptions}

Table 4 reports the PIPs recorded, according to the different drug classes, both in the whole population and in each subgroup. Irrespective of the drug classes, the total number of PIPs was 538, corresponding to $10.6 \%$ of the total prescriptions. Percentages were quite similar when considering the $\mathrm{NH}$ and $\mathrm{MC}$ groups ( $11 \%$ and $10 \%$, respectively); conversely, VS subjects were found to have lower number of PIPs (56, corresponding to $8.8 \%$ ). Reporting PIPs as percentage of the total prescriptions, however, somewhat "dilutes" the 
Table 2 Top ten prescriptions

\begin{tabular}{|c|c|c|c|c|c|c|c|c|c|c|c|}
\hline \multicolumn{3}{|l|}{ Whole sample } & \multicolumn{3}{|l|}{ NH patients } & \multicolumn{3}{|l|}{ MC patients } & \multicolumn{3}{|l|}{ VS subjects } \\
\hline Drug & $\begin{array}{l}\text { No of } \\
\text { patients }\end{array}$ & (\%) & Drug & $\begin{array}{l}\text { No of } \\
\text { patients }\end{array}$ & (\%) & Drug & $\begin{array}{l}\text { No of } \\
\text { patients }\end{array}$ & (\%) & Drug & $\begin{array}{l}\text { No of } \\
\text { patients }\end{array}$ & (\%) \\
\hline ASA & 304 & 35.3 & Esomeprazole & 85 & 59.9 & ASA & 220 & 38.5 & ASA & 51 & 34.9 \\
\hline Furosemide & 193 & 22.4 & Furosemide & 64 & 45.1 & Furosemide & 111 & 19.4 & Furosemide & 18 & 12.3 \\
\hline Ramipril & 122 & 14.2 & ASA & 33 & 23.2 & Omeprazole & 96 & 16.8 & Bisoprolol & 17 & 11.6 \\
\hline Esomeprazole & 114 & 13.2 & Ramipril & 30 & 21.1 & Ramipril & 77 & 13.5 & Simvastatin & 17 & 11.6 \\
\hline Omeprazole & 106 & 12.3 & Quetiapine & 30 & 21.1 & Bisoprolol & 72 & 12.6 & Atorvastatin & 16 & 11 \\
\hline Bisoprolol fumarate & 100 & 11.6 & Allopurinol & 29 & 20.4 & Amlodipine & 64 & 11.2 & Ramipril & 15 & 10.3 \\
\hline Levothyroxine & 92 & 10.6 & Parnaparin & 24 & 16.9 & Atorvastatin & 64 & 11.2 & Rosuvastatin & 15 & 10.3 \\
\hline Amlodipine & 90 & 10.5 & Trazodone & 23 & 16.2 & Levothyroxine & 63 & II & Levothyroxine & 14 & 9.6 \\
\hline Atorvastatin & 89 & 10.3 & Sennosides & 22 & 15.5 & Pantoprazole & 60 & 10.5 & Lorazepam & 14 & 9.6 \\
\hline Allopurinol & 83 & 9.1 & Lactulose & 21 & 14.8 & Metformin & 56 & 9.8 & Atenolol & 13 & 8.9 \\
\hline
\end{tabular}

Note: The table reports the most frequent prescriptions in the whole sample and in each subgroup, the data are expressed as both number and relative percentage of the patients taking the specific drug.

Abbreviations: ASA, acetylsalicylic acid; MC, memory clinic; NH, nursing home; VS, volunteer subjects.

Table 3 Total prescription distribution according to ATC classes

\begin{tabular}{llll}
\hline ATC code & Site of action & $\begin{array}{l}\text { Number of } \\
\text { prescriptions }\end{array}$ & Percentage \\
\hline C & Cardiovascular system & 1,584 & 31.1 \\
N & Nervous system & 1,078 & 21.2 \\
A & Alimentary tract and metabolism & 1,023 & 20.1 \\
B & Blood and blood forming organs & 599 & 11.8 \\
M & Musculoskeletal system & 248 & 4.87 \\
H & Systemic hormonal preparations (excluding sex & 164 & 3.2 \\
& hormones and insulins) & & \\
R & Respiratory system & 121 & \\
G & Genitourinary system and sex hormones & 89 & 1.75 \\
S & Sensory organs & 63 & 1.24 \\
L & Antineoplastic and immunomodulating agents & 44 & 0.86 \\
D & Dermatologicals & 23 & 0.45 \\
J & Antiinfectives for systemic use & 19 & 0.37 \\
P & Antiparasitic products, insecticides, and repellents & 19 & 0.37 \\
V & Various & 13 & 0.25 \\
\hline Not & 19 & \\
\hline
\end{tabular}

Note: The table reports the complete distribution of the medications in the whole sample according to their relative ATC class.

Abbreviation: ATC, anatomical therapeutic chemical.

Table 4 PIPs according to the Beers criteria

\begin{tabular}{|c|c|c|c|c|c|c|c|c|}
\hline \multirow[t]{2}{*}{ Drug class } & \multicolumn{2}{|c|}{ Whole sample } & \multicolumn{2}{|c|}{ NH patients } & \multicolumn{2}{|c|}{ MC patients } & \multicolumn{2}{|c|}{ VS subjects } \\
\hline & No & $\%$ & No & $\%$ & No & $\%$ & No & $\%$ \\
\hline Cardiovascular & $85(8.9)$ & 1.6 & $10(7)$ & I & $62(10.8)$ & 1.9 & $13(9)$ & 2.1 \\
\hline Acting upon platelet aggregation & $60(7.0)$ & 1.2 & $16(11.3)$ & $\mathrm{I} .4$ & $38(6.7)$ & I.I & $6(4.1)$ & 0.9 \\
\hline Gastrointestinal & $8(0.8)$ & 0.2 & $4(3.5)$ & 0.5 & $3(0.5)$ & 0.1 & 0 & 0 \\
\hline NSAID & $2(0.2)$ & 0 & 0 & 0 & 2 & 0.4 & 0 & 0 \\
\hline Antihistamines & II (I.2) & 0.3 & $7(4.9)$ & 0.7 & $4(0.7)$ & 0.1 & 0 & 0 \\
\hline For respiratory diseases & $2(0.2)$ & 0.0 & I (0.7) & 0.1 & $\mathrm{I}(0.2)$ & 0.0 & $0(0.0)$ & 0 \\
\hline \multicolumn{9}{|l|}{ CNS } \\
\hline Antiparkinson & $4(0.5)$ & 0.1 & $2(1.4)$ & 0.2 & $2(0.3)$ & 0.1 & $0(0.0)$ & 0 \\
\hline Antidepressant & $14(1.6)$ & 0.3 & $3(2.1)$ & 0.3 & $6(1.1)$ & 0.1 & $5(3.4)$ & 0.8 \\
\hline Antipsychotics & $97(11.1)$ & 1.9 & $61(42.8)$ & 5.4 & $36(6.4)$ & 0.9 & 0 & 0 \\
\hline Barbiturates & II (I.3) & 0.2 & $8(5.6)$ & 0.7 & $3(0.5)$ & 0.1 & $0(0.0)$ & 0 \\
\hline Benzodiazepines & $205(23.5)$ & 4.2 & $8(5.6)$ & 0.8 & $168(29.3)$ & 5 & $30(20.5)$ & 4.8 \\
\hline Nonbenzodiazepine hypnotics & $12(1.4)$ & 0.2 & $2(1.4)$ & 0.2 & $8(1.4)$ & 0.2 & $2(1.4)$ & 0.3 \\
\hline Drugs to be used with caution & $561(64.8)$ & $\mid 1.01$ & $132(92.9)$ & 11.6 & $378(66.3)$ & 11.2 & $51(34.9)$ & 7.9 \\
\hline
\end{tabular}

Notes: The table reports the PIPs received by the whole sample and by each subgroup; data are expressed as both number of subjects receiving the specific PIP (no) and percentages of PIPs referred to each specific drug class with respect to the total number of prescriptions (\%).

Abbreviations: CNS, central nervous system; NSAID, nonsteroidal anti-inflammatory drugs; PIP, prevalence of potentially inappropriate prescription; MC, memory clinic; $\mathrm{NH}$, nursing home; VS, volunteer subjects. 
impact of PIPs due to the high number of prescriptions. When expressing the data as percentage of patients coping with at least one PIP, similar results were noticed in the whole sample (44.4\%) and in MC patients (44.5\%). Very different was the case of $\mathrm{NH}$ patients, where this percentage reached $57.7 \%$, and VS subjects, where the value dropped down to $30.8 \%$. In particular, lorazepam was one of the most frequent PIP, both in the whole sample and subgroups, as well as many other benzodiazepines (summing up all the benzodiazepines, they constituted $40.2 \%$ of all PIPs). Although some of the considered benzodiazepines were not listed in the tables reported in the Beers criteria (American Geriatrics Society, 2012), from a general point of view, benzodiazepines of intermediate or long half-lives should be avoided for the treatment of insomnia, agitation, or delirium in the elderly. Nevertheless, whenever a diagnosis of anxiety or a risk of convulsions was present, the benzodiazepine prescription was considered as appropriate. All the prescriptions relating to triazolam were considered inappropriate as this compound, in Italy, is used only as a hypnotic. Ticlopidine and doxazosin were also very frequently prescribed, both in whole sample and subgroups (in total, 48 patients received doxazosin and 60 received ticlopidine). Antipsychotics were inappropriately prescribed 97 times in patients with dementia for the treatment of behavioral symptoms before trying nonpharmacological therapies, as suggested by Beers criteria and European Federation of the Neurological Societies' guidelines. ${ }^{8-20}$ Even if not expressed in Beers criteria, it is noteworthy that 26 patients did not receive a gastroprotective drug when indicated. Moreover, on grouping PIPs according to their ATC code, a prevalence of drugs belonging to the CNS system was found $(347 ; 67.8 \%$ of all PIPs), followed by the cardiovascular system $(85 ; 16.6 \%$ of all PIPs), blood and hematopoietic organs $(60 ; 11.7 \%$ of all PIPs), respiratory system (10; $1.9 \%$ of all PIPs), gastrointestinal system ( $8 ; 1.6 \%$ of all PIPs), and musculoskeletal system (2; $0.4 \%$ of all PIPs). Finally, it should be mentioned that the Beers criteria, in addition to PIPs, list a series of drugs to be used with caution in the elderly. In this regard, we found that, in the whole sample, $\sim 11 \%$ of prescriptions referred to drugs that needed to be used with caution in the elderly (Table 4). In particular, the cases most frequently detected in the present survey were: cardioaspirine for people aged $\geq 80$ years (184), selective serotonin reuptake inhibitors (152), and vasodilators (77).

\section{Characteristics of the patients receiving PIPs}

Comparing the characteristics of the patients coping with PIPs versus those who did not receive a PIP, the mean age of the two groups was superimposable ( $80.4 \pm 7.3$ and $80.2 \pm 7.4$ years, respectively) and females seemed to receive more PIPs than males (46.3\% vs $40.6 \%$ ), even if the difference did not reach a statistical significance $(\mathrm{F}[1,858]=1.348 ; P=0.246)$. The probability of running the risk of receiving a PIP was strictly dependent on the number of prescriptions; indeed, within the group of patients coping with at least one PIP, a statistically significant correlation was found between the total sum of all prescriptions and the number of PIPs $(r=0.400 ; P<0.001)$. Moreover, a significant correlation was observed between the number of illnesses and the probability of receiving a PIP ( $r=0.181 ; P<0.001)$; this result was also confirmed by data showing that the number of illnesses per patient was significantly different between patients who are receiving/not receiving at least one PIP $(\mathrm{F}[1,859]=20.897 ; P<0.001)$. In order to find the patients' or drug's characteristics that were more related to the inappropriate prescribing of a medication, various univariate analyses (ANOVA) were performed (Table 5), with the "number of PIPs" as dependent variable. Patients with a MMSE score $\leq 18$ received more PIPs than the other subjects $(\mathrm{F}[1,855]=10.216 ; P<0.05)$, although no significant difference in the number of illnesses was observed $(\mathrm{F}[1,858]=3.103 ; P=0.078)$. A similar difference was found when examining the Geriatric Depression Scale scores: patients with a Geriatric Depression Scale score $\geq 8$ considered depressed and received more PIPs than nondepressed individuals $(\mathrm{F}[1,591]=14.277 ; P<0.001)$. As expected, polypharmacy and the use of psychotropic drugs were all statistically significant, even considering antipsychotic, anxiolytic, and antidepressant drugs separately. No differences were found when considering age, sex, multiple comorbidities (even if this last parameter was close to significance: $P=0.068$, mirroring the weak correlation, previously described, between illnesses and the amount of PIPs) and using the admission to hospital or emergency department as independent variables.

\section{Sedative load}

The SL due to CNS-active drugs was calculated for each patient and the relative data are reported in Table 6 . In the whole sample, 209 patients $(24.1 \%)$ had a $\mathrm{SL} \geq 3$, which is considered elevated. The values were similar when considering MC and VS subgroups (22.5\% and $21.0 \%$, respectively), but they were quite different with respect to NH subjects, where $34.4 \%$ of patients had a SL $\geq 3$. This finding is in agreement with the data on the SL per patient; indeed, a statistically significant more elevated SL was detected in NH patients (SL mean: 1.97) in comparison to the other subgroups (SL mean in MC patients: 1.47 and VS subjects: 1.51) $(\mathrm{F}[2,857]=5.155 ; P<0.05)$. 
Table 5 Univariate analysis of the factors potentially influencing PIPs

\begin{tabular}{|c|c|c|c|}
\hline \multirow[t]{2}{*}{ Variable } & \multicolumn{2}{|c|}{ Mean number of PIPs per patient } & \multirow[t]{2}{*}{$P$-value } \\
\hline & In & Out & \\
\hline \multicolumn{4}{|l|}{ Sociodemographic characteristics } \\
\hline Age $\geq 85$ years & 0.61 & 0.63 & $P=0.702$ \\
\hline Female sex & 0.65 & 0.58 & $P=0.282$ \\
\hline \multicolumn{4}{|l|}{ Clinical and functional status characteristics } \\
\hline Multiple comorbidities ( $\geq 4$ diseases) & 0.65 & 0.52 & $P=0.068$ \\
\hline Cognitive impairment ( $\leq 18$ MMSE score) & 0.80 & 0.58 & $P<0.05$ \\
\hline Depression ( $\geq 8$ GDS score) & 0.75 & 0.49 & $P<0.001$ \\
\hline \multicolumn{4}{|l|}{ Service use characteristics } \\
\hline Emergency department over the past year & 0.66 & 0.59 & $P=0.226$ \\
\hline Hospital admission over the past year & 0.69 & 0.60 & $P=0.548$ \\
\hline \multicolumn{4}{|l|}{ Drug-related characteristics } \\
\hline Polypharmacy ( $\geq 4$ drugs) & 0.81 & 0.29 & $P<0.05$ \\
\hline Any psychotropic drug use ( $\geq$ I drugs) & 1.01 & 0.22 & $P<0.001$ \\
\hline Antipsychotics use & 1.49 & 0.50 & $P<0.001$ \\
\hline Anxiolytics use & 1.35 & 0.43 & $P<0.001$ \\
\hline Antidepressants use & 0.81 & 0.55 & $P<0.001$ \\
\hline
\end{tabular}

Abbreviations: GDS, Geriatric Depression Scale; MMSE, Mini-Mental State Examination; PIP, prevalence of potentially inappropriate prescription.

\section{Anticholinergic load}

The AL was calculated for each patient in the three groups and the relative data are reported in Table 6 . A total of $10.7 \%$ of the whole sample, corresponding to 92 patients, had an $\mathrm{AL} \geq 3$, which was considered inappropriate. ${ }^{17}$ Interestingly, the majority of these patients belonged to the $\mathrm{NH}$ group (46 patients). A significant difference among the subgroups was obtained following an ANOVA performed with the "anticholinergic load" as dependent variable and "group" as factor $(\mathrm{F}[2,843]=19.464 ; P<0.001)$. Post hoc comparisons revealed a significant difference between $\mathrm{NH}$ patients and the other two subgroups, but not between MC and VS patients (mean AL in NH patients was 1.62; MC patients was 0.92; and VS subjects was 0.83 ).

\section{Drug interactions}

In addition to the previously described issues, we reasoned that increasing the amount of prescriptions might also lead to a more elevated possibility of drug-drug interactions. Indeed, several interactions of potential clinical interest were observed in the whole sample. We detected 266 interactions, even up to five in three patients, which would have required a change in the prescribed drugs and 3,475 interactions of minor concern, requiring attention. The most frequent potential interactions (shown in Table 7) were those between allopurinol and ramipril (25 cases), citalopram and esomeprazole (16 cases), amiodarone and furosemide (12 cases). In order to compare the three subgroups, an ANOVA was performed with the "number of severe interactions" as

Table $6 \mathrm{SL}$ and $\mathrm{AL}$ scores

\begin{tabular}{llllll}
\hline SL score & Number of patients & Percentage of patients & AL score & Number of patients & Percentage of patients \\
\hline 0 & 324 & 37.7 & 0 & 389 & 45.3 \\
1 & 162 & 18.8 & 1 & 246 & 28.6 \\
2 & 165 & 19.2 & 2 & 133 & 15.5 \\
3 & 93 & 10.7 & 3 & 50 & 5.8 \\
4 & 52 & 6.0 & 4 & 17 & 1.9 \\
5 & 36 & 4.2 & 5 & 12 & 1.4 \\
6 & 19 & 2.2 & 6 & 10 & 1.2 \\
7 & 7 & 0.8 & 7 & 3 & 0.4 \\
8 & 1 & 0.1 & & & 100 \\
9 & 1 & 0.1 & & 860 & \\
Total & 860 & 100 & &
\end{tabular}

Note: The table reports the number of patients in the whole sample presenting a certain SL and AL score.

Abbreviations: AL, anticholinergic load; SL, sedative load. 
Table 7 Most frequent drug interactions

\begin{tabular}{ll}
\hline Drug interactions & $\begin{array}{l}\text { Number } \\
\text { of patients }\end{array}$ \\
\hline Allopurinol-ramipril & 25 \\
Citalopram-esomeprazole & 16 \\
Amiodarone-furosemide & 12 \\
Amiodarone-warfarin & 7 \\
Citalopram-quetiapine & 6 \\
Lansoprazole-citalopram & 6 \\
Amiodarone-hydrochlorothiazide & 6 \\
Sertraline-trazodone & 5 \\
Citalopram-ticlopidine & 5 \\
Potassium chloride-ramipril & 5 \\
Amlodipine-simvastatin & 5 \\
\hline Note: The table reports the most frequent drug interactions observed in the \\
whole sample.
\end{tabular}

a dependent variable and "group" as a factor, obtaining statistically significant values $(\mathrm{F}[2,843]=3.354 ; P<0.05)$. Post hoc analyses, however, did not allow observation of a statistical significance among the different subgroups.

\section{Antidementia drugs}

In the whole sample, only 20 patients received an acetylcholinesterase inhibitor (18) or memantine (two). Of these, eight were NH patients and 12 were MC patients. Examining the clinical diagnosis of each subject, 64 patients had Alzheimer's disease or mixed dementia, which, according to recent guidelines ${ }^{21}$ should have been treated with antidementia drugs; among these patients, only four received a pharmacological therapy for dementia. Moreover, $119 \mathrm{had}$ a diagnosis of generic cognitive impairment, being therefore potential candidates for this type of treatment.

\section{Discussion}

Inappropriateness of prescription represents a complex topic and an issue of major concern for the health care system. In the light of paucity of studies investigating this phenomenon in the Italian population, in the present research, we analyzed the prescriptions of 860 elderly subjects living in a small town of Lombardy, Italy.

The investigation revealed that nearly half of them (44.4\%) received at least one PIP; NH patients were more exposed, with $57.7 \%$ of them dealing with at least one or up to five PIPs. Our data are quite different from the ones obtained by other Italian and European studies. Concerning NH residents, in the study of Ruggiero et al, ${ }^{22}$ the prevalence was $35 \%$. With regard to outpatients, Maio et $\mathrm{a}^{23}$ found a prevalence of $18 \%$, while a retrospective cohort study ${ }^{24}$ reveals that $25.8 \%$ of outpatients received at least one prescription for any potentially inappropriate drugs; of these, 15.2\% were found to receive prescriptions for medications always identified as inappropriate. In case of outpatients, however, the data were not directly comparable because of the use of different criteria for determining medication inappropriateness. Conversely, our results are very similar to the ones obtained by Davidoff et al, ${ }^{25}$ who applied the Beers criteria to a large population study performed in US, found that $42.6 \%$ of persons had dealt with at least one PIP. With regard to $\mathrm{NH}$ patients, on the other hand, the high amount of PIPs may be due to the elevated number of demented patients (89.7\%), with $42.2 \%$ (corresponding to 60 patients) having a diagnosis of severe dementia. In all the subgroups, the most frequent inappropriate prescription concerned CNS-active drugs. This is largely due to the long-term use of benzodiazepines, which are considered inappropriate in the elderly, as they increase the risk of cognitive impairment and falls. However, another reason possibly explaining this phenomenon is the high number of demented patients treated with antipsychotic drugs before being treated with nonpharmacological therapies, as suggested by the international guidelines. ${ }^{8-20}$ Of concern are the data relative to SL and AL; to our knowledge, there are very few Italian studies examining these parameters in the elderly. Notably, both these parameters, if elevated, can have adverse consequences related to cognitive and physical functioning. ${ }^{13,14}$ One-fourth of our sample (24.1\%) had an elevated SL score, in particular the NH subgroup, where there was a high consumption of psychotropic drugs. The percentage of patients with a high $\mathrm{AL}$ was, on the other hand, $10.7 \%$. In addition to these indicators, we found 266 potentially relevant drug-drug interactions in our sample. Drug interactions are responsible for up to $2-3 \%$ of hospital admissions ${ }^{26}$ and for this reason many campaigns to improve appropriateness in general practice have been implemented during the last years. ${ }^{27}$ In our survey, medication underprescribing was observed in the case of antidementia drugs: only $20(10.9 \%)$ out of 183 patients, who were potential candidates for this treatment, received a cholinesterase inhibitor or memantine. Our percentage is lower than the one reported by Gruber-Baldini et al, ${ }^{28}$ who found a prevalence of treated dementia patients of $24.7 \%$. The reasons for undertreatment of dementia are unknown, but a negative attitude versus antidementia drugs is widespread among general practitioners. Multimorbidity, polypharmacy, agism, fear of adverse events, and economic problems may contribute to underprescription of antidementia drugs. Selected interventions may help to improve the quality of prescriptions, as suggested by 
Cherubini et al, ${ }^{29}$ not only for antidementia drugs, but also for drugs prescription in general. Indeed, adequate education and interventions within the domain of geriatric pharmacology can improve the recognition of drug-drug interaction and help to prevent adverse drug reactions. To this aim, various strategies can be adopted, such as the insertion of formal surveillance systems and built-in computer programs alerting in case of PIPs, and the involvement of a multidisciplinary geriatric team reviewing therapies. In addition, a number of educational actions can be taken within the hospitals. For example, as suggested by Petrovic et $\mathrm{al}^{30}$ for older adults, a global geriatric assessment may be helpful in improving the quality of prescribing.

\section{Limitations}

The present study has some limitations. First, the use of Beers' criteria may be criticized as, according to some authors, ${ }^{31}$ they are too focused on drugs available in the US market rather than in Europe. Nevertheless, using the revised criteria, as published by the American Geriatrics Society, ${ }^{8}$ we encountered only a few cases that needed discussion. The second limitation is related to the fact that we collected the medications indicated by the participants at the time of answering the questionnaire, therefore we cannot be sure about their effective pharmacological therapy, due to possible mistakes in reporting the correct therapy. Nevertheless, this is the only way to collect data. The third limitation is related to the fact that the subgroups are not similar in terms of sample size, and this aspect makes it difficult to compare them. However, our results highlight the existence of key areas within the current health practices that may be potentially improved to favor a more correct medication prescription.

\section{Compliance with ethical standards}

The study was not submitted to the ethical committee as it was based on an anonymous questionnaire reporting only the age and sex of the patient. The survey was not aimed to change clinical management of the individual patients. In addition the questionnaires were not coded, therefore the collected data following the input in the database cannot be associated with the individual patients. Formal informed consent was obtained for all patients, for patients with dementia consent from a relative was obtained. All principles outlined in the Declaration of Helsinki were followed.

\section{Acknowledgment}

We thank Piacenza and Vigevano foundations for the financial support.

\section{Disclosure}

The authors report no conflicts of interest in this work.

\section{References}

1. Laroche ML, Charmes JP, Nouaille Y, Nouaille Y, Picard N, Merle L. Is inappropriate medication use a major cause of adverse drug reactions in the elderly? Br J Clin Pharmacol. 2007;63(2):177-186.

2. Page RL, Ruscin JM. The risk of adverse drug events and hospitalrelated morbidity and mortality among older adults with potentially inappropriate medication use. Am J Geriatr Pharmacother. 2006;4(4): 297-305.

3. Poudel A, Hubbard RE, Nissen L, Mitchell C. Frailty: a key indicator to minimize inappropriate medication in older people. QJM. 2013; 106(10):969-975.

4. O'Connor MN, Gallagher P, O'Mahony D. Inappropriate prescribing: criteria, detection and prevention. Drugs Aging. 2012;29(6): 437-452.

5. Dimitrow MS, Airaksinen MS, Kivelä SL, Lyles A, Leikola SN. Comparison of prescribing criteria to evaluate the appropriateness of drug treatment in individuals aged 65 and older: a systematic review. JAGS. 2011;59(8):1521-1530.

6. Beers MH, Ouslander JG, Rollingher I, Reuben DB, Brooks J, Beck JC. Explicit criteria for determining inappropriate medication use in nursing home residents. UCLA Division of Geriatric Medicine. Arch Intern Med. 1991;151(9):1825-1832.

7. Fick DM, Cooper JW, Wade WE, Waller JL, Maclean JR, Beers MH. Updating the Beers criteria for potentially inappropriate medication use in older adults: results of a US consensus panel of experts. Arch Intern Med. 2003;163(22):2716-2724.

8. American Geriatrics Society. American geriatric society updated Beers criteria for potentially inappropriate medication use in older adults: the American Geriatrics Society 2012 Beers Criteria Update Expert Panel. J Am Geriatr Soc. 2012;60(4):616-631.

9. Gallagher P, Ryan C, Byrne S, Kennedy J, O'Mahony D. STOPP (Screening tool of older person's prescriptions) and START (Screening tool to alert doctors to right treatment). Consensus validation. Int J Clin Pharmacol Ther. 2008;46(2):72-83.

10. Hanlon JT, Lindblad CI, Hajjar ER, McCarthy TC. Update on drugrelated problems in the elderly. Am J Geriatr Pharmacother. 2003;1(1): $38-43$.

11. Maher RL, Hanlon J, Hajjar ER, McCharty TC. Clinical consequences of polypharmacy in elderly. Expert Opin Drug Saf. 2014;13(1):57-65.

12. Hines LE, Murphy JE. Potentially harmful drug-drug interactions in the elderly: a review. Am J Geriatr Pharmacother. 2011;9(6):364-377.

13. Linjakumpu T, Hartikainen S, Klaukka T, Koponen H, Kivela SL, Isoaho R. A model to classify the sedative load of drugs. Int J Geriatr Psychiatry. 2003;18(6):542-544.

14. Fox C, Smith T, Maidment I, et al. Effect of medications with anti-cholinergic properties on cognitive function, delirium, physical function and mortality: a systematic review. Age Ageing. 2014;43(5): 604-615.

15. Folstein MF, Folstein SE, McHugh PR. "Mini-mental state". A practical method for grading the cognitive state of patients for the clinician. J Psychiatr Res. 1975;12(3):189-198.

16. Measso G, Cavarzeran F, Zappalà G, et al. Il Mini Mental State Examination: studio normativo di un campione random della popolazione italiana. Dev Neuropsychol. 1993;9(2):77-85.

17. Carnahan RM, Lund BC, Perry PJ, Pollock BJ, Culp KR. The anticholinergic drug scale as a measure of drug-related anticholinergic burden. Associations with serum anticholinergic activity. J Clin Pharmacol. 2006;46(12):1481-1486.

18. Baxter K. Stockley's Drug Interactions, 9th ed. London: Pharmaceutical Press; 2010 .

19. IBM SPSS. Statistical Package for Social Science 15.0 for Windows. Chicago, IL. 2006. 
20. Waldemar G, Dubois B, Emre M, et al. Recommendations for the diagnosis and management of Alzheimer's disease and other disorders associated with dementia: EFNS guideline. Eur J Neurol. 2007;14(1):e1-e26.

21. Bond M, Rogers G, Peters J, et al. The effectiveness and cost-effectiveness of donepezil, galantamine, rivastigmine and memantine for the treatment of Alzheimer's disease (review of technology appraisal no. 111): a systematic review and economic model. Southampton: Health Technol Assess. 2012;16(21):1-470.

22. Ruggiero C, Lattanzio F, Dell'Aquila G, Gasperini B, Cherubini A. Inappropriate drug prescriptions among older nursing home residents: the Italian perspective. Drugs Aging. 2009;26(1):15-30.

23. Maio V, Yuen EJ, Novielli K, Smith KD, Louis DZ. Potentially inappropriate medication prescribing for elderly outpatients in Emilia Romagna, Italy. Drugs Aging. 2006;23(11):915-924.

24. Herrera MS, Del Canale MD, Brianti MD, Fabi MD, Louis MS. Improving the appropriateness of prescribing medicine in the elderly: a comprehensive approach in the Local Health Unit of Parma, Italy Population Health Matters (Formerly Health Policy Newsletter). 2010;23(2):3.
25. Davidoff AJ, Miller GE, Sarpong EM, Yang E, Brandt N, Fick D. Prevalence of potentially inappropriate medication use in older adults using the 2012 Beers criteria. JAGS. 2015;63(3):486-500.

26. Tragni E, Casula M, Pieri V, et al. Prevalence of the prescription of potentially interacting drugs. PLoS One. 2013;8(10):e78827.

27. Raschi E, Piccinni C, Signoretta V, et al. Clinically important drugdrug interactions in poly-treated elderly outpatients: a campaign to improve appropriateness in general practice. $\mathrm{Br} J$ Clin Pharmacol. 2015;80(6):1411-1420.

28. Gruber-Baldini AL, Stuart B, Zuckerman IH, Simoni-Wastila L, Miller R. Treatment of dementia in community-dwelling and Institutionalized Medicare Beneficiaries. JAGS. 2007;55(10):1508-1516.

29. Cherubini A, Corsonello A, Lattanzio F. Underprescription of beneficial medicines in older people: causes, consequences and prevention. Drugs Aging. 2012;29(6):463-475.

30. Petrovic M, van der Cammen T, Onder G. Adverse drug reactions in older people: detection and prevention. Drugs Aging. 2012;29(6):453-462.

31. Lam MP, Cheung BM. The use of STOPP/START criteria as a screening tool for assessing the appropriateness of medications in the elderly population. Expert Rev Clin Pharmacol. 2012;5(2):187-189.
Clinical Interventions in Aging

\section{Publish your work in this journal}

Clinical Interventions in Aging is an international, peer-reviewed journal focusing on evidence-based reports on the value or lack thereof of treatments intended to prevent or delay the onset of maladaptive correlates of aging in human beings. This journal is indexed on PubMed Central, MedLine,

\section{Dovepress}

CAS, Scopus and the Elsevier Bibliographic databases. The manuscript management system is completely online and includes a very quick and fair peer-review system, which is all easy to use. Visit http://www.dovepress. $\mathrm{com} /$ testimonials.php to read real quotes from published authors. 